\title{
A CARTA DE FEUERBACH A HEGEL
}

Adriana Veríssimo Serrão ${ }^{1}$

As três cartas que nos finais de 1828 acompanham o envio da dissertação De ratione, una, universali, infinita apresentada por Ludwig Feuerbach à Universidade de Erlangen, embora de desigual relevo quanto ao conteúdo filosófico, formam no seu conjunto um documento de especial interesse para a compreensão da biografia intelectual de Feuerbach.

A carta a Schelling, à época professor em Munique, é concisa, cerimoniosa e meramente circunstancial $^{2}$. Para Johann Paul Harl, professor em Erlangen e membro do júri, Feuerbach redige uma sinopse desenvolvida que explicita o tema central da dissertação - a demonstração da essência da razão - e recapitula alguns tópicos argumentativos. Unicamente o pensar corresponde à essência da razão, porque só quando pensa o indivíduo se desliga de si mesmo para se ligar a outros seres pensantes, tornando-se assim membro de uma comunidade sem divisões, não limitada por uma ordem superior, nem interrompida interiormente por nenhuma diferença. Se a sensação está presa ao senciente - quando sinto, "eu sou eu" - e nos sentimentos, como o amor e a amizade, sou "eu com outros", conservando cada um, o eu e o outro, a respectiva individualidade, ao pensar, o indivíduo participa de uma esfera comum onde se anulam as condições privada, pessoal ou intersubjectiva, tornando-se num ser universal. Deste modo, o pensar, tal como a consciência que o acompanha, não deve ser considerado uma faculdade subjectiva, mas sim uma actividade comunitária, una e infinita.

A determinação da razão enquanto pensamento e o primado da cogitatio sobre o cogito não se colocam, neste primeiro trabalho, no quadro de uma filosofia do conhecimento. Traçando uma direcção constante ao longo da obra posterior, a reflexão sobre a natureza da razão é conduzida numa perspectiva onto-antropológica, como condição real da possibilidade da fundação, e da manutenção, da comunidade humana. A unidade universal da razão é, por isso, equiparada, sem mais, à unidade universal dos homens - "a unidade dos homens nada mais exprime ou significa do que a unidade da própria razão" - e esta, por sua vez, protagonizada pela Humanidade enquanto um género - "ao pensar, eu próprio sou o género humano, não o homem singular que sou quando sinto, vivo, ajo, nem um certo homem qualquer (este ou

\footnotetext{
1 Doutora em Filosofia, Universidade de Lisboa, Departamento de Filosofia, Centro de Filosofia da Universidade de Lisboa. E-mail : adrianaserrao@fl.ul.pt

2 Carta a Friedrich Wilhelm Joseph von Schelling (18 de Dezembro de 1828); L. Feuerbach. Gesammelte Werke (= GW), hrsg. von Werner Schuffenhauer, Berlin, Akademie Verlag, 1967 e ss., vol.17, pp. 113-114.
} 
aquele), mas ninguém." ${ }^{13} \mathrm{O}$ pensar é simultaneamente a essência da razão e a essência do homem.

A imagem mais usada para retratar esta visão da imanência não é a do tempo sucessivo, mas a do espaço simultâneo, omni-englobante, ilimitado e sem partes, no qual as consciências subjectivas, embora separadas em diferentes lugares físicos, estão permanentemente reunidas no elemento da consciência universal; assim, enquanto uns dormem, outros estão a pensar, continuando a actividade pensante a envolvê-los, sem nunca sofrer interrupções. Outro argumento da dissertação retomado nesta carta invoca o erro como marca do limite e sinal da distância entre finito e infinito: se o indivíduo isolado fosse, ou tivesse em si, o pensar, nada mais haveria para além dele, deixando de existir o erro, ao contrário do sentir que nunca erra, dada a coincidência do senciente com as suas sensações ${ }^{4}$.

A carta dirigida a Hegel destaca-se pela amplitude reflexiva. Em vez de um resumo das teses, Feuerbach transforma-a numa indicação programática, no enunciado das grandes linhas para o futuro da filosofia. Invocando a qualidade de aluno presencial em Berlim, entre o semestre de Verão de 1824 e o semestre de Inverno de 1825-26, onde frequenta, com excepção das Lições de Estética, todos os cursos de Hegel - "Lógica e Metafísica", "Filosofia da Religião", "Filosofia da História Universal", "Direito Natural e Ciência Política", "Filosofia do Espírito ou Antropologia e Psicologia", "História da Filosofia", "Filosofia da Natureza ou Física Racional"5 -, Feuerbach assume a apropriação do "espírito especulativo" colhido nos

\footnotetext{
3 De ratione, una, universali, infinita, GW, vol. 1, respectivamente p. 96 e p. 12. Com a dissertação manuscrita De infinitate, unitate atque communitate rationis, Feuerbach obtém em 25 Junho de 1828 o grau de doutor em Filosofia. A versão impressa, revista e ampliada, com o título De ratione, una, universali, infinita foi apresentada como Habilitationsschrift e defendida com sucesso em provas públicas a 6 de Dezembro, com a finalidade de obter a licentia docendi para ensinar como Privatdozent. Concedida a 13 de Fevereiro de 1829, a licença régia para dar "lições sobre temas (Gegenstände) da filosofia" iniciaria o curto período de professor de "História da Filosofia" e "Lógica e Metafísica" na Friedrich-Alexander-Universität de Erlangen.

4 Carta a Johann Paul Harl (início de Dezembro de 1828), GW, vol. 17, pp. 109-113.

5 Para a reconstituição dos anos universitários, veja-se a Introdução de Werner Schuffenhauer ao volume 1 dos Gesammelte Werke. Entre as principais biografias intelectuais de Feuerbach, com importantes informações sobre a fase estudantil, são de consultar: Karl Grün, Ludwig Feuerbach in seinem Briefwechsel und Nachlaß, sowie in seiner philosophischen Charakterentwicklung, Leipzig und Heidelberg: C. F. Winter Verlag, 1874, vol. I; Wilhelm Bolin, Ludwig Feuerbach. Sein Wirken und seine Zeitgenossen. Mit Benutzung ungedruckten Materialsl, Stuttgart: Cotta, 1891; Wilhelm Bolin, "Biographische Einleitung" in: Ausgewählte Briefe von und an Ludwig Feuerbach. Zum Säkulargedächtnis seiner Geburt, Leipzig: Otto Wigand, 1904, Bd. 1, pp. 3-211; depois em: Ludwig Feuerbach. Sämtliche Werke, Bd. XII, Stuttgart, 1964; Adolf Kohut, Ludwig Feuerbach. Sein Leben und seine Werke. Mit ungedruckten Briefen von L. Feuerbach und Anselm Ritter v. Feuerbach, Leipzig: Fritz Eckard, 1909; Gustav Radbruch, Die Familie Feuerbach, eine geistige Dynastie. Gestalten und Gedanken. Acht Studien, Leipzig, 1944; 2. a ed. ampliada: Zehn Studien,
}

\begin{tabular}{|l|l|l|l|l|}
\cline { 2 - 4 } & Ano 8 & n. 14 & Janeiro-Julho 2019 & p. $235-247$ \\
\hline
\end{tabular}


ensinamentos e ideias do mestre, mas já na figura de um pensador livre, não de um seguidor escolar.

Será importante recordar o contexto desta estreita relação de discípulo a mestre, que longe de ter acontecido ocasionalmente foi escolhida por Feuerbach, quando ainda estudante de teologia em Heidelberg solicitara ao pai autorização para a transferência de curso e de universidade. Mudar de teologia para filosofia significava tout court estudar a filosofia em Berlim e com Hegel. Anuência difícil, fruto de demorada ponderação por parte de Paul Johann Anselm, já porque o diploma de teologia permitiria o acesso imediato a um lugar de pastor, garantindo a colocação profissional de um membro de uma família numerosa, já porque o seu racionalismo crítico rejeitava a posição de uma filosofia única e definitiva:

[...] mais tarde ou mais cedo estarás inteiramente certo de que [...] nunca existiu uma filosofia única, mas sempre e só filósofos; de que há, sempre houve e sempre haverá tantas filosofias quantas as cabeças pensantes que procuram compreender de si para si mesmas o inconcebível e o inapreensível; quem corta artificialmente o sistema das suas opiniões através de "ses" e "porques" e "portantos" e o vende como uma ciência (objectiva), ou mesmo como a ciência das ciências, ou é um sofista ou alguém confundido na auto-ilusão ${ }^{6}$.

Em contraste, a insistência, dramatizada pelo jovem de vinte e um anos, sublinhava o desinteresse pelas aulas e a insatisfação com matérias que se repartiam entre a aridez da exegética bíblica e obscuridade do misticismo. Dos professores de Heidelberg, apenas a orientação especulativa de Karl Daub permitia vislumbrar um conceito filosófico de Deus, anunciando-se por esta via, não pelo cepticismo moralizante dos kantianos, nem pelo sentimentalismo exaltado dos românticos, o ansiado encontro com a Ciência ${ }^{7}$ : "tudo me chama para Berlim e para longe de Heidelberg" ${ }^{8}$. Também a Daub confessa o seu desapontamento com a estreiteza dos temas teológicos e deixa claro que o desejo da filosofia, mais do que um objecto de estudo, se confunde o ideal de abraçar a inteireza da vida - "abstraindo da sua existência

Stuttgart, 1954; Uwe Schott, Die Jugendentwicklung Ludwig Feuerbachs bis zum Fakultätswechsel 1825. Ein Beitrag zur Genese der Feuerbachschen Religionskritik. Mit einem bibliographischen Anhang zur Feuerbach-Literatur, Göttingen: Vandenhoeck \& Ruprecht, 1973; Hans-Martin Sass, Ludwig Feuerbach in Selbstzeugnissen und Bilddokumenten, Reinbeck bei Hamburg: Rowohlt, 1978; Joseph Winiger, Ludwig Feuerbach. Denker der Menschlichkeit. Eine Biographie, Berlin: Aufbau Taschenbuch Verlag, 2004; Francesco Tomasoni, Ludwig Feuerbach. Biografia intelletuale, Brescia: Morcelliana, 2011.

\footnotetext{
Carta de Paul Johann Anselm von Feuerbach (20 de Abril de 1825), GW, vol. 17, p. 82.

Carta a Paul Johann Anselm von Feuerbach (Outono de 1823), GW, vol. 17, pp. 33-38.

8 Carta a Paul Johann Anselm von Feuerbach (8 de Janeiro de 1824), GW, vol.17, p. 42.
}

\begin{tabular}{|l|l|l|l|l|}
\cline { 2 - 4 } & Ano 8 & n. 14 & Janeiro-Julho 2019 & p. $235-247$ \\
\hline
\end{tabular}


empírica, o filósofo é homem absolutamente universal" ${ }^{9}$-, numa visão da totalidade identificada pelos pólos do Homem e da Natureza:

Eu sou como uma alma ávida e ambiciosa que quer abarcar em si e consumir tudo, não porém como um agregado empírico, mas sim como totalidade sistemática; o meu exigir é ilimitado, incondicionado: quero gravar a Natureza no meu coração, em face de cuja profundidade o cobarde teólogo recua, cujo sentido o físico compreende mal, cuja salvação unicamente o filósofo leva a cabo. Quero gravar no meu coração o Homem, mas o Homem inteiro... ${ }^{\mathbf{1 0}}$.

A doutrina de Hegel corresponderá inteiramente à expectativa alimentada do encontro com abertura mental do filósofo e à descoberta do amplo mundo do espírito, desde logo associada à filosofia no seu mais alto expoente, como ciência da apreensão da realidade em um todo sistemático, mesclando-se a afinidade intelectual com a mais elevada imagem da pessoa do professor:

\begin{abstract}
Sim, mantive com Hegel uma relação mais íntima, mais proveitosa do que com qualquer outro dos nossos antepassados espirituais, porque o conheci pessoalmente; fui durante dois anos o seu ouvinte, o seu ouvinte atento, incondicional, entusiasmado. Não sabia o que queria e devia fazer, tão desfeito e dilacerado estava quando cheguei a Berlim; mas mal o ouvira durante meio ano, já a minha cabeça e coração se encontravam recompostos por ele; sabia o que devia e queria fazer: Não teologia, mas filosofia! Não tagarelar e delirar, mas aprender! Não acreditar, mas pensar! Foi com ele que cheguei à consciência de mim e à consciência do mundo. Foi a ele que chamei outrora o meu segundo pai, tal como a Berlim o meu lugar de nascimento espiritual. Foi o único homem que me deixou sentir e perceber o que é um professor, o único em quem encontrei o sentido para esta palavra antes tão oca, a quem me senti ligado pela profunda gratidão. [....] O meu professor foi, portanto, Hegel, eu, o seu aluno; não o nego, reconheço-o ainda com gratidão e alegria, talvez hoje melhor do que outrora. ${ }^{11}$
\end{abstract}

Não é difícil colher em múltiplos depoimentos autobiográficos convergentes o que teria sido, no geral, o resultado dessa frequência. Não tanto a aprendizagem de conteúdos, a preferência dirigida para uma ou outra disciplina específica, quanto o contacto com o puro trabalho do pensamento, o acesso a um método que se servia exclusivamente do pensar e rejeitava o recurso à intuição e à fé, método esse condensado na lógica enquanto organon da filosofia, como escreve o irmão no termo do ciclo berlinense:

9 Carta a Karl Daub (29 de Janeiro de 1825), GW, vol.17, p. 62.

10 Carta a Paul Johann Anselm von Feuerbach (22 de Março de 1825), GW, vol.17, pp. 71-72.

11 Werner Schuffenhauer, "'Verhältnis zu Hegel'. Ein Nachlaßfragment von Ludwig Feuerbach", Deutsche Zeitschrift für Philosophie, Berlin, 30 (1982), 509-510. O requerimento dirigido ao Rei solicitando a autorização para ensinar contém o registo das cadeiras feitas e o elenco dos professores de Berlim: Schleiermacher e Neander em Teologia, van der Hagen e Böckh em Filologia, Erman em Física, Ideler em Matemática e Astrognosia, Ranke em História, von Henning em Teoria da Cor; Carta a Luís I, Rei da Baviera (5 de Agosto de 1828), GW, vol. 17, p. 101.

\begin{tabular}{|l|l|l|l|l|}
\cline { 2 - 4 } & Ano 8 & n. 14 & Janeiro-Julho 2019 & p. $235-247$ \\
\hline
\end{tabular}


Já estou despachado do Hegel; com excepção da Estética frequentei todas as suas lições, frequentei a Lógica mesmo duas vezes. Mas a Lógica de Hegel é como que o corpus juris, as Pandectas da filosofia; ela contém a filosofia inteira, tanto a antiga como a moderna, segundo os seus princípios de pensamento; ela é acima de tudo a apresentação do seu método. O mais importante é precisamente apoderar-se não apenas do conteúdo, mas também do método de uma filosofia. ${ }^{12}$

Entre a saída de Berlim e a matrícula em Erlangen, onde, dando cumprimento aos regulamentos bávaros, deveria terminar o curso, medeia uma fase mal conhecida. Numa escola dominada por um forte núcleo de pietistas e em cujo corpo docente, parco em bons professores de filosofia, apenas pontificavam kantianos sem brilho, os "críticos" preocupados em determinar "se e como se pode ver, antes de se ver"13, Feuerbach dedica esse último ano a cadeiras de ciências da Natureza - botânica, anatomia, fisiologia -, mas não de filosofia. Redigida num ambiente pouco estimulante, a tese sobre a universalidade da razão trazia à Baviera a influência de Berlim e lançava sobre o doutorando vindo de fora a suspeição de adepto da filosofia especulativa. Perfilhar um espírito especulativo significava, porém, para ele algo muito diferente de um hegelianismo obediente. Significava prosseguir a racionalização consumada por Hegel como termo de um ciclo histórico, e nessa medida finalizada, para a ampliar, passando uma outra ordem das coisas, isto é, levando a filosofia para fora da filosofia. A tensão entre acabamento - o saber de si do pensar consumado no interior do pensar - e inacabamento - a necessidade de transpor os limites da escola para ganhar corpo no todo da Humanidade - é o motor do andamento futurizante impresso no motivo da realização (Verwirklichung) e mundanização (Verweltlichung) da ideia. Porque só a filosofia especulativa, porque realizada em si mesma, se podia realizar fora dela, mas sem se realizar fora dela, não estaria cumprida na sua vocação e capacidade de racionalização do mundo.

A instauração desta consciência universal a ser assumida pela Humanidade no seu conjunto não poderia emergir da continuidade com os procedimentos da filosofia académica. A incarnação do Logos, que congrega como eixo principal os diversos tópicos desta carta-manifesto, deveria ser conduzida por uma nova "espécie de filosofar", interveniente e não só compreensiva, combativa e não só hermenêutica. A descida do "céu" à "terra" não se cumpre por via estético-literária como expressão de intuições poéticas, nem se limita a uma vulgarização da filosofia. Como radicação da verdade e preparação do futuro, responde à urgência do tempo e ganha uma feição prática.

12 Fragmente zur Charakteristik meines philosophischen curriculum vitae, GW, vol.10, p. 155.

13 Carta ao irmão Eduard (Dezembro de 1827), GW, vol.17, p. 95.

\begin{tabular}{|l|l|l|l|l|}
\cline { 2 - 4 } & Ano 8 & n. 14 & Janeiro-Julho 2019 & p. $235-247$ \\
\hline
\end{tabular}


Das duas principais linhas que configuram a mentalidade da época moderna, aqui enunciadas como esboço de uma filosofia da história, ambas centradas na subjectividade - o "eu penso" cartesiano e o "eu creio" luterano - só a primeira teria sido verdadeiramente superada como princípio da filosofia, e apenas no interior dela. Repousando sobre o si-mesmo (Selbst), divino e humano, sustentado num eu firme, substancializado, o cristianismo é o reduto da subjectividade endeusada, reproduzida à escala humana e levada ao clímax na figura da alma imortal persistindo num além fora do tempo mundano. Daí que a religião se coloque face à filosofia não só como concepção do mundo concorrente, mas sobretudo como efectivo obstáculo que quebra o continuum do género humano e nele introduz focos de cisão; como antítese da filosofia, é o "outro da razão". Porque entra mais fundo na humanidade dos homens, exercendo mais forte influência sobre a consciência comum ao apelar a representações, sentimentos e crenças, promessas de salvação individual num mundo melhor, o fundamento da religião tem de ser pura e simplesmente erradicado.

Tal como para Platão o caminho para a verdade não poderia coexistir com a influência sedutora dos divulgadores de mitos, sendo imperioso o seu afastamento dos muros da cidade, para Feuerbach, a fundação de uma nova época governada pela luz exclusiva da razão tem como condição primeira o desaparecimento da subjectividade como modo da intuição (Anschauungsweise). O anúncio de um combate sem tréguas, sem conciliação possível, entre poderes lutando pela dominação e cuja vitória final só será alcançada com a destronação da autonomia do Selbst imprime à carta a Hegel um tom eminentemente político.

Está fora de causa, no actual estado da recepção de Feuerbach, circunscrever o interesse deste texto à discussão erudita sobre o seu hegelianismo ou examinar a fidelidade da pretensa recepção de Hegel, controvérsia que marcou décadas da literatura. O silenciamento da subjectividade do absoluto hegeliano a favor de um absoluto comunitário e objectivo; a ausência da dialéctica a favor da aniquilação do contrário numa unidade total e sem diferenças; a inflexão antropológica na eleição do género como único portador do espírito - são sinais evidentes de que Feuerbach não está já a expor Hegel, mas a delinear marcos de um percurso pessoal. Dois anos mais tarde, a primeira grande obra, os Gedanken über Tod und Unsterblichkeit, articulará subjectividade e dualismo como duas faces da mesma atitude de

\begin{tabular}{|l|l|l|l|l|}
\cline { 2 - 4 } & Ano 8 & n. 14 & Janeiro-Julho 2019 & p. $235-247$ \\
\hline
\end{tabular}


cisão, logo, de irracionalidade, na crítica conjunta à ideia de imortalidade da alma e à desvalorização da Natureza decorrente da posição do espírito criador $^{14}$.

Formulados com clareza, numa expressão livre da formalidade contida da carta, três motivos de divergência com princípios fundamentais do pensamento de Hegel, compõem o fragmento coetâneo, ou ligeiramente anterior porque datado de 1827-28, com o título "Zweifel". Em primeiro lugar, a reabilitação da Natureza como ser imediato, liberta do estatuto de "posta pelo espírito" ou derivada de um acto espiritual prévio. Em segundo, a impossível conciliação da filosofia e da religião, distinguindo-se na religião, por um lado, a "fé", por outro, as "doutrinas da fé", ou seja, a teologia. Por último, a transformação da filosofia como consciência recapitulativa do passado em filosofia dirigida para o futuro.

\section{Dúvida}

Como se relaciona o pensar com o ser, a Lógica com a natureza? Está fundada a transição daquela a esta? Onde está a necessidade, onde está o princípio desta passagem? Sem dúvida que, no interior da Lógica, vemos determinações simples como ser, nada, algo, finito, infinito, essência, fenómeno transitarem umas nas outra e superarem-se, mas elas são em si mesmas determinações abstractas, unilaterais, negativas; uma pergunta apenas: como pode então a ideia, enquanto a totalidade que abarca em si todas estas determinações, ser posta em igual categoria precisamente com estas determinações finitas? A necessidade da progressão lógica é a própria negatividade das determinações lógicas. Mas o que é então o negativo na ideia absoluta, completa? O facto de ela ser apenas e ainda no elemento do pensar? De onde é que sabes que há ainda um outro elemento? Da Lógica? De modo algum; pois precisamente a partir de si a Lógica apenas sabe de si, apenas sabe do pensar. Logo, o outro da Lógica só pode ser deduzido da Lógica não logicamente, mas ilogicamente, i.e., a Lógica apenas transita na natureza, porque o sujeito pensante, encontra previamente uma existência imediata, uma Natureza e é constrangido, dado o posicionamento natural, a reconhecê-la. Se não houvesse uma Natureza, nunca a imaculada virgem Lógica produziria uma a partir de si.

Como se relaciona a filosofia para com a religião? - Hegel insiste muito na concordância da filosofia com a religião, nomeadamente com as doutrinas da religião cristã, embora capte a religião apenas como um patamar

14 Sobre o debate do hegelianismo do jovem Feuerbach, que marcou, por via indirecta, uma fase da descoberta do pensamento de Feuerbach, devem consultar-se: Simon Rawidowicz, Ludwig Feuerbachs Philosophie. Ursprung und Schicksal, Berlin: W. De Gruyter, 2.a ed. 1964 [1.a ed.: 1931], pp. 9-20; Claudio Cesa, Il giovane Feuerbach, Bari: Laterza, 1963; Max W. Wartofsky, Feuerbach. Cambridge/ London/ New York/ Melbourne: Cambridge University Press, 1977; Claudio Cesa, Introduzione a Feuerbach, Roma: Laterza, 1978; Manuel Cabada Castro, Feuerbach y Kant. Dos Actitudes antropológicas, Madrid: Comillas, 1980, pp. 21-23; Alexis Philonenko, La jeunesse de Feuerbach. Introduction à ses positions fondamentales (1828-1841), 1. vol. Paris : Vrin, 1990; Gabriel Amengual, "Gattungswesen als Solidarität. Die Auffassung vom Menschen in der Bestimmung des Gattungswesens als Begriff und Grundlegung der Solidarität", in: Ludwig Feuerbach und die Philosophie der Zukunft. Berlin: Akademie Verlag, 1990, pp. 345-367; Christine Weckwerth, Ludwig Feuerbach. Zur Einführung, Hamburg: Junius Verlag, 2002.

\begin{tabular}{|l|l|l|l|l|}
\cline { 2 - 5 } & Ano 8 & n. 14 & Janeiro-Julho 2019 & p. $235-247$ \\
\hline
\end{tabular}


do espírito. As religiões existentes contêm sem dúvida muito de repugnante e incompatível com a verdade, mas não deveria a própria religião ser captada de modo mais geral e a concordância da filosofia com ela ser posta apenas no reconhecimento e justificação de certas doutrinas? Existe alguma outra concordância?

Como se relaciona a filosofia de Hegel com o presente e o futuro? Não é ela o mundo passado como mundo de pensamento? É ela mais do que uma recordação da Humanidade daquilo que foi, mas não é mais? ${ }^{15}$

Não se conhece qualquer resposta de Hegel a esta carta impregnada de ousadia e originalidade. Seja qual for a perspectiva de análise adoptada - anúncio do espírito do tempo e documento inaugural do movimento Jovem-hegeliano ou embrião do pensamento maduro de Feuerbach -, a carta de Feuerbach a Hegel permanece, pelo seu ímpeto interveniente e pelo radicalismo de um projecto de racionalidade integral, um documento ainda e sempre aberto à interpretação ${ }^{16}$.

A Carta de Feuerbach a Hegel foi publicada pela primeira vez por Karl Grün em Ludwig Feuerbach in seinem Briefwechsel und Nachlaß, sowie in seiner philosophischen Charakterentwicklung, Leipzig und Heidelberg: C. F. Winter Verlag, 1874, vol. I, pp. 214-219. A presente tradução segue o texto dos Gesammelte Werke, na edição de Werner Schuffenhauer,

15 Fragmente zur Charakteristik meines philosophischen curriculum vitae, GW, vol.10, 155-156.

16 Entre as múltiplas análises e interpretações diversas desta Carta: Horst Stuke, Philosophie der Tat. Studien zur Verwirklichung der Philosophie bei den Jung-hegelianern und wahren Sozialisten, Stuttgart: Ernst Klett Verlag, 1963; Joachim Ritzkowski, Ludwig Feuerbachs Angriff gegen das Christentum. Die Bedeutung des Frühwerks Feuerbachs für die Religionskritik, Berlin: 1969 (Diss. Phil.), pp. 18-19; Peter Cornehl, Die Zukunft der Versöhnung. Eschatologie und Emanzipation in der Aufklärung, bei Hegel und in der Hegelschen Schule, Göttingen: Vandenhoeck \& Ruprecht, 1971, pp. 218-221; Erich Thies, "Die Verwirklichung der Vernunft. Ludwig Feuerbachs Kritik der spekulativ-systematischen Philosophie", Revue Internationale de Philosophie 26, n. ${ }^{\circ} 101$ (1972), pp. 283-293; Hans-Jürg Braun, Die Religionsphilosophie Ludwig Feuerbachs. Kritik und Annahme des Religiöse, Stuttgart-Bad Cannstatt: Friedrich Frommann Verlag-Günther Holzboog, 1972, pp. 41-43; Heinz-Hermann Brandhorst, Lutherrezeption und bürgerliche Emanzipation. Studien zum Luther- und Reformationsverständnis im deutschen Vormärz (1815-1848) unter besonderer Berücksichtigung Ludwig Feuerbachs, Göttingen: Vandenhoeck und Ruprecht, 1981, pp. 96 ss; Wofgang Essbach, Die Junghegelianer. Soziologie einer Intellektuellengruppe, München: Wilhelm Fink Verlag, 1988, pp. 169-172; Ursula Reitemeyer, Philosophie der Leiblichkeit. Ludwig Feuerbachs Entwurf einer Philosophie der Zukunft, Frankfurt a.M.: Suhrkamp, 1988, pp. 17-24; Charles A. Wilson, Feuerbach and the Search for Otherness, New York/ Bern/ Frankfurt a. M. / Paris: Peter Lang, 1989, pp. 123-130; José Barata-Moura, A "realização da razão". Um programa hegeliano?, Lisboa; Caminho, 1990, pp. 39-42.

\begin{tabular}{|c|c|c|c|c|}
\hline Qenista Dialectus & Ano 8 & n. 14 & Janeiro - Julho 2019 & p. $235-247$ \\
\hline
\end{tabular}


Berlin: Akademie Verlag, 1967 e ss, vol. 17, pp. 103-108, que inclui as notas à margem constantes do manuscrito.

\section{A Georg Wilhelm Friedrich Hegel}

Ansbach, 22 de Novembro de 1828

Excelentíssimo Senhor

Mui venerado Professor

Tomo a liberdade de enviar a Vossa Senhoria a minha dissertação. Não por lhe atribuir qualquer valor particular ou por imaginar que ela tenha algum interesse em si mesma e para o espírito de Vossa Senhoria; apenas lha envio, porque eu, o autor, me encontro para consigo na relação especial de um discípulo directo, uma vez que frequentei durante dois anos os seus cursos em Berlim e porque gostaria tão-só de lhe testemunhar por este meio a minha elevada estima e veneração pessoal, que lhe devo enquanto meu mestre e que reconheço com alegria também como minha obrigação. Mas justamente esta relação especial de discípulo directo produz ao mesmo tempo em mim a timidez com que lhe dirijo o meu trabalho. Porque quando o discípulo não testemunha nem expressa a elevada estima e a autêntica veneração pelo seu mestre mediante actos exteriores ou palavras e sentimentos, mas apenas pelas suas obras, só o conseguirá precisamente mediante obras que tenham sido elaboradas segundo o espírito do seu professor, que sejam dignas desse espírito como o de um aluno e que preencham as exigências que se depositam num discípulo directo. Ora, justamente perante a minha obra, se é que a minha dissertação é digna deste nome, eu próprio reconheço demasiado bem o que é deficiente, insuficiente, falível e censurável, não a devendo por isso considerar, antes pelo contrário, como uma obra adequada às exigências que só eu próprio me impus e àquelas que o seu magistério de dois anos, tão instrutivo e rico de ensinamentos, produziu. Se é certo que o motivo de muitas falhas e deficiências deve ser procurado em geral apenas nos estreitos limites do âmbito, da finalidade e da linguagem de uma dissertação, e para mais no domínio da filosofia, e que tanto de criticável se desculpa por si mesmo, todavia eu só posso perdoar-me esta minha liberdade de lhe apresentar a minha dissertação pela consciência, que publicamente confesso, de ela respirar no todo e no geral um espírito especulativo, de ela (certamente como um mero

\begin{tabular}{|l|l|l|l|l|}
\cline { 2 - 4 } & Ano 8 & n. 14 & Janeiro-Julho 2019 & p. $235-247$ \\
\hline
\end{tabular}


fragmento arrancado por uma circunstância exterior) ser o produto de um estudo que ao apreender e acolher em si a alma, a própria força produtiva e autónoma, consiste numa assimilação e formação viva, quer dizer, essencial (não formal), livre (porque de modo algum arbitrária, que vai escolhendo e tirando daqui e dali), das ideias ou conceitos que formam o conteúdo das obras e exposições orais do Senhor Professor; pela consciência de que as ideias produzidas ou despertadas por si em mim e expressas na sua filosofia não se mantêm lá no alto, no geral, acima do sensível e do fenómeno, mas continuam a actuar em mim de maneira criadora, saindo por assim dizer do céu da sua pureza incolor, da sua luz imaculada, da sua beatitude e unidade consigo mesmas para se afundarem e ganharem forma numa intuição que penetra o particular, que no fenómeno e face ao fenómeno supera e vence os fenómenos; e ainda pela consciência de que esta minha dissertação, pelo menos no geral e embora de um modo muitíssimo imperfeito, ainda bastante grosseiro e deficiente, de um modo que não evita o abstracto, traz contudo em si um vestígio de uma espécie de filosofar a que se poderia chamar a realização* e mundanização da ideia, a ensarcose ou a incarnação do Logos puro. Ora, apesar da limitação do meu trabalho, que eu próprio reconheço e sinto, esta consciência dá-me a coragem de o apresentar a Vossa Senhoria. Estou também firmemente convencido de que esta espécie de filosofar, que ainda não desligada nem liberta de mim mesmo se vislumbra mal neste trabalho, que está presente dentro de mim ainda em estado embrionário e talvez nunca chegue, pelo menos por meu intermédio, à existência e à configuração acabada, chegou ao seu tempo ou (o que é o mesmo) se funda no próprio espírito da filosofia moderna e da filosofia mais recente, proveio desse mesmo espírito. Pois se se trata da filosofia tal como é denominada pelo Senhor Professor, não como um assunto da escola mas da Humanidade, se o espírito, pelo menos o da mais recente filosofia, exige e obriga a romper as barreiras de uma escola e tornar-se numa visão universal, histórico-mundial e revelada, e se precisamente nesse espírito reside não apenas a semente de um melhor exercício e de uma melhor actividade literária, mas ainda a semente de um espírito universal que se proclama na realidade, como que a semente de um novo período da história, trata-se então agora de fundar, por assim dizer um reino ${ }^{*}$, o reino da ideia, do pensamento que é consciente de si mesmo e que se contempla a si mesmo em tudo o que existe; trata-se de derrubar do seu trono dominador o Eu, o si-mesmo, que especialmente

\footnotetext{
[nota à margem]: mas não deve ser de modo algum a popularização ou a tradução do pensar numa intuição contemplativa, nem dos pensamentos em imagenzinhas ou sinais.

** [nota à margem]: o fundador deste reino não terá certamente um nome, não será um indivíduo, ou será este indivíduo, o único que existe, o espírito do mundo.
}

\begin{tabular}{|l|l|l|l|l|}
\cline { 2 - 4 } & Ano 8 & n. 14 & Janeiro-Julho 2019 & p. $235-247$ \\
\hline
\end{tabular}


desde o começo da era cristã tem dominado o mundo e se tem apreendido como o único espírito que existe, e fazendo-se valer como absoluto reprimiu o verdadeiro espírito absoluto e objectivo, para que a ideia seja e domine efectivamente, para que uma só luz brilhe em tudo e através de todas as coisas e o velho reino de Ormuz e Ahriman - o dualismo em geral - seja vencido, não pela crença numa Igreja fora do mundo, virada sobre si, ou pela ideia de uma única substância, ou em geral por um modo de filosofar que tem um além, um negativo, uma relação de exclusão para com um outro (o que sempre aconteceu na história até hoje), mas pelo conhecimento da razão que tem consciência de si como sendo toda a realidade, una e universal, existente e cognoscente, real, omnipresente, da razão que não está separada nem cindida de si mesma por nenhuma diferença. Chegará então, e terá finalmente de chegar, este domínio exclusivo da razão; a filosofia que desde há milhares de anos trabalhava para o seu acabamento e realização, mas que ao elevar-se sempre por graus encerrava sempre o Todo, o Universo (ou como se lhe queira chamar) numa determinidade particular, num conceito determinado, e que assim deixava necessariamente ficar fora dela um outro (fosse ele a determinidade e a própria existência em geral, fosse a religião, ou a Natureza, ou o Eu, etc.), que finalmente agora captou o próprio todo num todo e o exprimiu na forma de um todo, tem agora finalmente de conseguir que não subsista mais um segundo ou um outro, seja com a ilusão, o direito e a exigência a ser uma segunda verdade, como a verdade da religião, etc.; formas e concepções milenárias que desde a primeira criação natural atravessam toda a história como princípios fundamentais têm de desaparecer, já que chegou, embora ainda não se tenha tornado manifesto, o conhecimento da sua nulidade e finitude, e tudo se tornará ideia e razão. Trata-se agora de um novo fundamento das coisas, de uma nova história, de uma segunda criação em que não mais existirá o tempo além e fora do pensamento, mas em que a razão se tornará a forma universal da intuição das coisas. Se, como se pode claramente provar, o homem se torna culpado da mais louca contradição quando se limita a falar das coisas como separadas e cindidas do pensamento e, mais ainda, quando afirma que o pensar é algo de subjectivo e de não-real, quando, pelo contrário, o homem tal como as próprias coisas não existem de modo algum fora do pensar, pois o pensar é o que tudo engloba, o verdadeiro espaço universal de todas as coisas e sujeitos e, além do mais, cada coisa e sujeito só são o que são por meio da representação e no pensamento que se tem deles, é claro que se o $\mathrm{Eu}$, o si-mesmo (bem como a infinita multiplicidade que a ele se liga) é suprimido no conhecimento como o absolutamente firme, como princípio universal e determinante do mundo e da intuição, ele desaparece da própria

\begin{tabular}{|l|l|l|l|l|}
\cline { 2 - 4 } & Ano 8 & n. 14 & Janeiro-Julho 2019 & p. $235-247$ \\
\hline
\end{tabular}


intuição; é então claro que o si-mesmo deixa de ser o que fora até aí; acaba mesmo por morrer. Por isso, não se trata agora de um desenvolvimento dos conceitos na forma da sua universalidade, na sua pureza separada e no seu ser-em-si isolado, mas de aniquilar verdadeiramente as anteriores concepções histórico-mundiais acerca do tempo, morte, aquém, além, eu, indivíduo, pessoa, e da pessoa intuída fora da finitude, no absoluto e como absoluta, a saber, como Deus, etc.; concepções essas nas quais está contido o fundamento da história até hoje e também a fonte do sistema das representações cristãs, tanto ortodoxas como racionalistas; trata-se de sondar o fundamento da verdade e de aí fazer penetrar em vez delas o conhecimento como intuição imediatamente presente e determinante do mundo, que na filosofia moderna se encontra confundido com um reino do em-si e do além sob a forma da verdade e da universalidade nua. É por isso que o cristianismo não pode ser considerado como a religião acabada e absoluta, que só pode consistir no reino da realidade da ideia e da razão existente. $\mathrm{O}$ cristianismo nada mais é do que a religião do si-mesmo puro, da pessoa enquanto único espírito que em geral existe e é por isso apenas o oposto do mundo antigo. Que significado tem, por exemplo, a Natureza nesta religião? Que posição desprovida de espírito e de pensamento tem nela a Natureza? E contudo é justamente esta ausência de espírito e de pensamento um dos seus pilares fundamentais. Sim, a Natureza está lá como inconcebida, misteriosa, inapreendida na unidade do ser divino, de tal modo que unicamente a pessoa (não a Natureza, o mundo, o espírito) celebra a sua salvação, que deveria consistir no conhecimento dela. É por isso que a razão ainda não se salvou no cristianismo. Por isso, também a morte, sendo embora um acto meramente natural, é ainda considerada de um modo inteiramente espiritual pelo mais indispensável jornaleiro na vinha do Senhor, para quem a obra da salvação só está completa para o perfeito discípulo e companheiro de Cristo. Sendo que o fundamento e a raiz de cada religião reside na filosofia, num modo de intuição determinado apenas no qual a religião se sustenta, é possível demonstrar da maneira mais precisa e mais concludente o que é finito e negativo, o que é pressentido pelo próprio cristianismo como um além. De uma maneira geral, todas as religiões não foram até hoje senão a presença imediata, a aparição e o fenómeno do espírito universal de uma filosofia que se mantém como una na diferença dos sistemas, por exemplo, a filosofia grega; o cristianismo foi o fenómeno da filosofia pós-grega que se propagou na forma de uma finitude fixa. No entanto, o esforço de cada um deveria neste momento tender para que o espírito exista como espírito e para que, na sua manifestação, nada seja senão ele mesmo. Mas vou interromper, com receio de ultrapassar os limites da modéstia

\begin{tabular}{|l|l|l|l|l|}
\cline { 2 - 4 } & Ano 8 & n. 14 & Janeiro-Julho 2019 & p. $235-247$ \\
\hline
\end{tabular}


e do respeito, se quisesse, meu profundamente venerado Professor, retê-lo mais longamente comigo, com a exposição das minhas ideias, dos meus esforços e do meu pensamento. $\mathrm{Na}$ esperança de que queira acolher com benevolência esta minha carta e o envio da minha dissertação, que mostra, pelo menos na generalidade, um estudo filosófico e um esforço para a presentificação imediata de ideias abstractas, fico no mais profundo respeito e sincera veneração

De Vossa Senhoria muito reconhecido Ludwig Feuerbach, Dr. em Filosofia

Permito-me ainda notar que para não incomodar Vossa Senhoria com uma carta demasiado extensa, abstive-me de falar em pormenor da minha dissertação e de mencionar em particular o que eu próprio ainda reconheço como incorrecto e imperfeito, bem como de salientar o tema principal que tenho agora presente com inteira clareza, embora tivesse sido também importante para mim eliminar muita coisa má, pelo menos por meio da expressa indicação e consciência, antes que Vossa Senhoria honrasse o meu trabalho lendo-o. Pela mesma razão, evitei uma carta pormenorizada, como o tema em si teric certamente exigido.

O presente artigo reproduz, com ligeiras modificações, a primeira publicação em Razão e Liberdade. Homenagem a Manuel José do Carmo Ferreira, Lisboa: Centro de Filosofia da Universidade de Lisboa, 2009, pp. 1309-1321.

\begin{tabular}{|l|l|l|l|l|}
\cline { 2 - 4 } Q & Ano 8 & n. 14 & Janeiro-Julho 2019 & p. 235-247 \\
\hline
\end{tabular}

